\title{
Process and product innovation in a vertically differentiated industry
}

\author{
Emanuele Bacchiega, ${ }^{*}$ Luca Lambertini ${ }^{*}, \#, \S$ Andrea Mantovani* \\ * Department of Economics, University of Bologna \\ Strada Maggiore 45, 40125 Bologna, Italy \\ \# ENCORE, University of Amsterdam \\ Roetersstraat 11, WB1018 Amsterdam, The Netherlands \\ $\S$ Paul Nitze School of Advanced International Studies \\ Johns Hopkins University Bologna Center \\ via Belmeloro 11, 40126 Bologna, Italy \\ bacchieg@spbo.unibo.it, lamberti@spbo.unibo.it, mantovan@spbo.unibo.it
}

February 13, 2007 


\begin{abstract}
We examine a vertically differentiated duopoly where firms invest in process and product innovation and then compete in prices under full market coverage. We show that (i) process and product innovation are complements (substitutes) for the low-quality (high-quality) firm; (ii) the firm which is initially more efficient invests more than the rival in process innovation; (iii) if the initial differential between marginal costs is sufficiently high, the demand for the less efficient firm is nil and the duopoly equilibrium does not exist.
\end{abstract}

Keywords: vertical differentiation; quality; R\&D

JEL: L13, O31 


\section{Introduction}

The analysis of vertically differentiated market conveys two main messages, that can be summarised by saying that (i) if quality improvements mainly hinge upon fixed costs, the number of firms that can survive at equilibrium with positive profits is finite, and (ii) there exists an incentive for earlier entrants to fill quality niches starting from the top. Claim (i) is known as the finiteness property (see Gabszewicz and Thisse, 1979, 1980, and Shaked and Sutton, 1982, 1983). The existing literature has produced several extensions of the basic model to investigate, inter alia, the relative incentives of high- and low-quality firms to carry out R\&D for product innovation, i.e., quality improvement, either cooperatively or noncooperatively (see Beath et al., 1987, Motta, 1992, Rosenkranz, 1995). The properly dynamic analysis of innovation in the form of quality improvement, and its relationship with patentability, has partly put into question the robustness of result (ii), highlighting the possibility that entering earlier than rivals may not go along with an incentive to fill top quality niches, as saving time means saving upon R\&D costs and may ultimately entail that earlier entrants start serving the market with low-quality goods (see Dutta et al., 1995; van Dijk, 1996; Lambertini and Tedeschi, 2006).

Notwithstanding the fact that, as casual observation suggests, product and process innovation very often coexist in firms' $R \& D$ portfolios, ${ }^{1}$ the interplay between investments for quality improvement and marginal cost reduction has been rarely analysed so far, with the relevant exception of Bonanno and Haworth (1998). They examine a vertically differentiated duopoly where either the high- or the low-quality firm may choose whether to activate an $R \& D$ project for either process or product innovation. One of their findingds is that, under Bertrand competition, the high-quality firm prefers to

\footnotetext{
${ }^{1}$ To this regard, see, e.g., Athey and Schmutzler (1995) and Cohen and Klepper (1996).
} 
carry out product $\mathrm{R} \& \mathrm{D}$ while the low-quality firm prefers to activate process $R \& D$. The intuitive explanation for this result is that, all else equal, increasing the high quality leads to an increase in the degree of differentiation, while increasing the low-quality yields the opposite.

In the present paper, we further explore the issue of $R \& D$ portfolios composed by process and product innovation activities in vertically differentiated industries, relying upon a model by Schmitt (2003) as a benchmark. As in Schmitt (2003), a vertically differentiated duopoly is investigated, under the assumption of full market coverage and variable costs of quality improvement. Addidionally, firms are initially endowed with different marginal costs and may invest in both types of R\&D. Market interaction takes the form of Bertrand competition, as usual under full coverage.

Our main findings can be summarised as follows. While both firms always invest to develop their respective qualities, they drastically differ as to the relative inventives to carry out process innovation. Indeed, we find that the highest investment for process innovation is carried out at equilibrium by the firm characterised by the lowest initial marginal cost, irrespective of whether such a firm is offering the high- or low-quality product. The ultimate consequence of this fact is that, provided the initial cost differential is large enough, then the less efficient firm is driven out of business by the rival and the duopoly equilibrium does not exist. Additionally, the present setup allows us to examine the presence of complementarity or substitutability between different activities in a firm's $R \& D$ portfolio. In this respect, quite unlike the current wisdom on this matter, ${ }^{2}$ we find out that product and process innovations are complements for the low-quality firm while they are substitutes for the high-quality firm. While the first conclusion is intuitive and fully in line with previous results, the second one is surprising, at least

\footnotetext{
${ }^{2}$ See Athey and Schmutzler (1995), Lambertini and Orsini (2000), Lin and Saggi (2002), Lambertini (2003, 2004), Lin (2004).
} 
at first sight. However, it can be interpreted on the basis of the attraction exerted by the median consumer on both firms under full coverage. While both cost reduction and quality improvement drive the low-quality firm in the right direction (that is, towards the median consumer), they drive the high-quality firm in the wrong one (that is, away from the median consumer). Therefore any marginal cost decrease by the high-quality firm must be accompanied by a lower investment in quality upgrading in order to keep the firm as close as possible to the median consumer.

We also consider the case in which firms cooperate at the process R\&D stage and characterise the optimal investment effort. We discover that only the most efficient firm invests when they are asymmetric at the outset, while no investment is carried out when they start from a symmetric position.

The remainder of the paper is organised as follows. The setup is laid out in section 2. The game is analysed in section 3. Section 4 tackles the issue in a cooperative scenario. Section 5 contains concluding remarks.

\section{The model}

A continuum of consumers of mass 1 is uniformly distributed over the interval $[\underline{\theta}, \bar{\theta}]$ with $\underline{\theta}=\bar{\theta}-1>0$ and density equal to one. A generic consumer identified by a marginal willingness to pay for quality $\theta \in[\underline{\theta}, \bar{\theta}]$ is characterised by the indirect utility function $U=\theta q_{i}-p_{i}$ if the consumer buys, $U=0$ if he/she does not. $q_{i}$ and $p_{i}$ are the quality and price of the product sold by firm $i$. The market is supplied by two firms, $H$ and $L$, that offer vertically differentiated products characterised by quality levels $q_{H}>q_{L}$. We assume that the market is fully covered, with the consumer who is indifferent between purchasing $q_{H}$ and $q_{L}$ located at $\widehat{\theta}=\left(p_{H}-p_{L}\right) /\left(q_{H}-q_{L}\right)$. Accordingly, market demands are:

$$
x_{H}=\bar{\theta}-\widehat{\theta} ; x_{L}=1-x_{H}=\widehat{\theta}-\underline{\theta} .
$$


Production costs borne by firm $i=H, L$ are $C_{i}=\left(c_{i}+s q_{i}^{2}\right) x_{i}$. This amounts to assuming that marginal production cost is the sum of a firmspecific (quality-independent) component $c_{i}$ plus a quality-specific component convex in the quality level, $s q_{i}^{2}$, where $s>0$ is a constant parameter common to both firms. Additionally, firms carry out R\&D activities for process innovation, i.e., the reduction of $c_{i}$. These activities involve a cost $\Gamma_{i}=\gamma k_{i}^{2}$, where $\gamma>0$ and $k_{i}$ is the individual R\&D effort. The outcome of $\mathrm{R} \& \mathrm{D}$ activity is a firm-specific component of the marginal cost equal to:

$$
c_{i}=\bar{c}_{i}-k_{i}-\beta k_{j}
$$

where, as in d'Aspremont and Jacquemin (1988), parameter $\beta \in[0,1]$ measures the positive externality received from the rival's investment. In line with Schmitt (2003, p. 74), we mainly focus on the case $\bar{c}_{H}>\bar{c}_{L}$; however, for the sake of completeness, we will also briefly examine the opposite case where $\bar{c}_{L} \geq \bar{c}_{H}$.

The objective function of firm $i$ is:

$$
\pi_{i}=\left(p_{i}-c_{i}-s q_{i}^{2}\right) x_{i}-\gamma k_{i}^{2}
$$

Firms play non-cooperatively a three-stage game where the first stage is for process $R \& D$, the second is for the development of quality and the third takes place in the price space. In each stage, firms play simultaneously. As usual, we shall proceed by backward induction to characterise the subgame perfect equilibrium. 


\section{The game}

The second and third stage can be quickly dealt with, as they closely reflect the analysis carried out by Schmitt (2003). Equilibrium prices are:

$$
\begin{aligned}
p_{H}^{*} & =\frac{2 c_{H}+c_{L}+(\bar{\theta}+1)\left(q_{H}-q_{L}\right)+s\left(2 q_{H}^{2}+q_{L}^{2}\right)}{3} \\
p_{L}^{*} & =\frac{c_{H}+2 c_{L}+(\bar{\theta}-1)\left(q_{H}-q_{L}\right)+s\left(2 q_{H}^{2}+q_{L}^{2}\right)}{3}
\end{aligned}
$$

while equilibrium qualities are:

$$
q_{H}^{*}=\frac{16 s\left(c_{H}-c_{L}\right)+3(4 \bar{\theta}+1)}{24 s} ; q_{L}^{*}=\frac{16 s\left(c_{H}-c_{L}\right)+3(4 \bar{\theta}-5)}{24 s} .
$$

Note that

$$
q_{H}^{*}-q_{L}^{*}=\frac{3}{4 s},
$$

entailing that the the degree of product differentiation is independent of the firm-specific cost differential between firms.

Moreover, observe that, on the basis of (2) and (5), one can describe the interplay between product and process innovation through the following partial derivatives:

$$
\begin{aligned}
& \frac{\partial q_{H}^{*}}{\partial k_{H}}=\frac{\partial q_{H}^{*}}{\partial\left(c_{H}-c_{L}\right)} \cdot \frac{\partial\left(c_{H}-c_{L}\right)}{\partial k_{H}}=\frac{2}{3}(\beta-1) \leq 0 ; \\
& \frac{\partial q_{L}^{*}}{\partial k_{L}}=\frac{\partial q_{L}^{*}}{\partial\left(c_{H}-c_{L}\right)} \cdot \frac{\partial\left(c_{H}-c_{L}\right)}{\partial k_{L}}=\frac{2}{3}(1-\beta) \geq 0,
\end{aligned}
$$

that immediately entail the following:

Proposition 1 From the standpoint of firm $H$ (resp., L), product and process innovation are substitutes (resp., complements) for all $\beta \in[0,1)$. The two RGD activities are independent within the firm if $\beta=1$. 
The main message conveyed by Proposition 1 is that there exists a synergy between $R \& D$ activities only within the low-quality firm, while boosting $R \& D$ for process innovation is detrimental to quality enhancement (and conversely) for the high-quality firm. This fact can be intuitively interpreted in the following terms. Of course, any increase in productive efficiency (i.e., a decrease in $c_{i}$ ) lowers equilibrium price and therefore makes either firm more aggressive, all else equal. As far as firm $L$ is concerned, it is also obvious that any increase in the quality level entails a gain in terms of market share: hence, firm $L$ approaches the median (and average) consumer by investing in both directions. On the contrary, any quality increase by firm $H$ drives it farther away from the same consumer. Consequently, the R\&D portfolio of the high-quality firm cannot feature complementarity as this would ultimately entail that firm $H$ 's product might be driven out of the spectrum of consumers' preferred qualities. In terms of price effect (which is driven by marginal costs) and demand effect (which is instead driven by location choices along the quality spectrum), this boils down to saying that while firm $L$ is on the "right side" (i.e., below the median consumer), firm $H$ is on the "wrong side" (i.e., above the median consumer).

Now we proceed to the characterization of the optimal behaviour of firms at the first stage, where they set R\&D investments for process innovation. Plugging the equilibrium expressions (4-5) into (3), we obtain the relevant profit functions at the first stage:

$$
\pi_{H}=\frac{\left[16 s\left(c_{H}-c_{L}\right)-9\right]^{2}}{432 s}-\gamma k_{H}^{2} ; \pi_{L}=\frac{\left[16 s\left(c_{H}-c_{L}\right)+9\right]^{2}}{432 s}-\gamma k_{L}^{2}
$$

where $c_{H}$ and $c_{L}$ are as in (2). From first order conditions (FOCs) we get 
optimal R\&D efforts:

$$
\begin{aligned}
& k_{H}^{*}=\frac{(1-\beta)\left[3 \gamma(9-16 s \Delta \bar{c})-32 s(1-\beta)^{2}\right]}{3 \gamma\left[27 \gamma-32 s(1-\beta)^{2}\right]} ; \\
& k_{L}^{*}=\frac{(1-\beta)\left[3 \gamma(9+16 s \Delta \bar{c})-32 s(1-\beta)^{2}\right]}{3 \gamma\left[27 \gamma-32 s(1-\beta)^{2}\right]} .
\end{aligned}
$$

where $\Delta \bar{c} \equiv \bar{c}_{H}-\bar{c}_{L}$.As a result, marginal costs are:

$$
\begin{aligned}
c_{H}^{*} & =\frac{27 \gamma\left(3 \gamma \bar{c}_{H}-1+\beta^{2}\right)-16 s(1-\beta)^{2}\left[3 \gamma \Delta \bar{c}-2\left(1-\beta^{2}\right)\right]}{3 \gamma\left[27 \gamma-32 s(1-\beta)^{2}\right]} ; \\
c_{L}^{*} & =\frac{27 \gamma\left(3 \gamma \bar{c}_{L}-1+\beta^{2}\right)-16 s(1-\beta)^{2}\left[3 \gamma \Delta \bar{c}-2\left(1-\beta^{2}\right)\right]}{3 \gamma\left[27 \gamma-32 s(1-\beta)^{2}\right]} .
\end{aligned}
$$

Therefore

$$
c_{H}^{*}-c_{L}^{*}=\frac{27 \gamma \Delta \bar{c}}{27 \gamma-32 s(1-\beta)^{2}} .
$$

The corresponding profits are:

$$
\begin{aligned}
\pi_{H}^{*} & =\frac{\left[27 \gamma-16 s(1-\beta)^{2}\right]\left[3 \gamma(9-16 s \Delta \bar{c})-32 s(1-\beta)^{2}\right]^{2}}{144 \gamma s\left[27 \gamma-32 s(1-\beta)^{2}\right]^{2}} ; \\
\pi_{L}^{*} & =\frac{\left[27 \gamma-16 s(1-\beta)^{2}\right]\left[3 \gamma(9+16 s \Delta \bar{c})-32 s(1-\beta)^{2}\right]^{2}}{144 \gamma s\left[27 \gamma-32 s(1-\beta)^{2}\right]^{2}} .
\end{aligned}
$$

The above expressions are both positive iff $\gamma>16 s(1-\beta)^{2} / 27$.

Using (11-12), optimal qualities rewrite as follows:

$$
\begin{aligned}
q_{H}^{*} & =\frac{9 \gamma[3(4 \bar{\theta}+1)+16 s \Delta \bar{c}]-32 s(1-\beta)^{2}(4 \bar{\theta}+1)}{8 s\left[27 \gamma-32 s(1-\beta)^{2}\right]} ; \\
q_{L}^{*} & =\frac{9 \gamma[3(4 \bar{\theta}-5)+16 s \Delta \bar{c}]-32 s(1-\beta)^{2}(4 \bar{\theta}-5)}{8 s\left[27 \gamma-32 s(1-\beta)^{2}\right]}
\end{aligned}
$$

There remains to check payoffs' local concavity and strategies' stability. Local concavity is always satisfied since

$$
\frac{\partial^{2} \pi_{i}}{\partial k_{i}^{2}}=-\frac{32}{27} s(1-\beta)^{2} \leq 0 \text { for all } \beta \in[0,1] .
$$


As to stability, we have to check the absolute value of the slope of best reply functions. The equilibrium is stable iff:

$$
\left|\frac{\partial k_{i}}{\partial k_{j}}\right|=\frac{16 s(1-\beta)^{2}}{27 \gamma-32 s(1-\beta)^{2}}<1,
$$

holding for all $\gamma>32 s(1-\beta)^{2} / 27$. This can be summarised by:

Lemma 2 While local concavity always holds, stability conditions require $\gamma>32 s(1-\beta)^{2} / 27$.

The above Lemma is largely in line with the discussion of concavity and stability carried out by Henriques (1990) about the well known d'Aspremont and Jacquemin $(1988,1990)$ Cournot model with process innovation.

We assume that the stability condition is satisfied. Note that, considering $\Delta \bar{c}>0, k_{L}^{*}>k_{H}^{*}$ and $c_{H}^{*}>c_{L}^{*}$ always. This is surely true if $k_{H}^{*}>0$. However, $k_{H}^{*}$ is non-positive for all

$$
\Delta \bar{c} \geq \frac{27 \gamma-32 s(1-\beta)^{2}}{48 \gamma s}
$$

therefore, in such a range, $k_{H}^{*}=0$. By plugging $k_{H}^{*}=0$ into (8) and solving the optimization problem for the low-quality firm, we obtain:

$$
\left.k_{L}^{*}\right|_{k_{H}^{*}=0}=\frac{(1-\beta)(9+16 s \Delta \bar{c})}{27 \gamma-32 s(1-\beta)^{2}}>0 .
$$

Furthermore, observe the expressions of equilibrium quantities:

$$
x_{H}^{*}=\frac{3 \gamma(9-16 s \Delta \bar{c})-32 s(1-\beta)^{2}}{2\left[27 \gamma-32 s(1-\beta)^{2}\right]} ; x_{L}^{*}=\frac{3 \gamma(9+16 s \Delta \bar{c})-32 s(1-\beta)^{2}}{2\left[27 \gamma-32 s(1-\beta)^{2}\right]} .
$$

As in the case of optimal $\mathrm{R} \& \mathrm{D}$ efforts, also here we have $x_{L}^{*}>x_{H}^{*}$ always. Moreover, $x_{H}^{*}=0$ if (20) holds. As a consequence, whenever the duopoly equilibrium is sustainable, $\pi_{L}^{*}>\pi_{H}^{*}$, as can be easily ascertained from (14$15)$.

Accordingly, we may state: 
Proposition 3 Provided stability holds, the duopoly equilibrium exists, with $k_{L}^{*}>k_{H}^{*}>0, x_{L}^{*}>x_{H}^{*}>0, c_{H}^{*}>c_{L}^{*}>0$ and $\pi_{L}^{*}>\pi_{H}^{*}>0$, for all $\Delta \bar{c} \in\left(0, \frac{27 \gamma-32 s(1-\beta)^{2}}{48 \gamma s}\right)$.

For all $\Delta \bar{c} \geq\left[27 \gamma-32 s(1-\beta)^{2}\right] /(48 \gamma s), x_{H}^{*}=k_{H}^{*}=0$. That is, the high-quality firm has no demand and carries out no R\&D for process innovation (whereby its profits are also nought), notwithstanding the fact that it indeed potentially supplies a positive quality level. In particular, from (5), one can easily verify that, in correspondence of $\Delta \bar{c}=\left[27 \gamma-32 s(1-\beta)^{2}\right] /(48 \gamma s)$,

$$
q_{H}=\frac{\bar{\theta}+1}{2 s} ; q_{L}=\frac{2 \bar{\theta}-1}{4 s} .
$$

That is, $q_{L}$ corresponds to the preferred quality of the median (and average) consumer, while $q_{H}$ is above the quality level that is preferred by the richest consumer in the market. Moreover, $q_{L}$ also corresponds to the quality that the low-quality firm would choose if it were appointed the leader's role at the quality stage. ${ }^{3}$ The reason for this result is that any increase in the basic cost differential $\Delta \bar{c}$ beyond the critical threshold $\left[27 \gamma-32 s(1-\beta)^{2}\right] /(48 \gamma s)$ cannot further modify qualities since the low-quality firm is already supplying the preferred quality of the median consumer. Any further increase would immediately trigger leapfroffing by the rival.

If one allows for the possibility that $\Delta \bar{c}<0$, it can be easily shown that the results are the mirror image of what previously obtained, with firms exchanging their respective roles. In particular, the duopoly equilibrium exists when $\Delta \bar{c} \in\left(-\frac{27 \gamma-32 s(1-\beta)^{2}}{48 \gamma s}, 0\right)$ and in this case $k_{H}^{*}>k_{L}^{*}>$ $0, x_{H}^{*}>x_{L}^{*}>0, c_{L}^{*}>c_{H}^{*}>0$ and $\pi_{H}^{*}>\pi_{L}^{*}>0$. If firm $H$ enjoys an

\footnotetext{
${ }^{3}$ For the derivation of the preferred quality of a generic consumer in the interval $[\underline{\theta}, \bar{\theta}]$, see Cremer and Thisse (1994). For the Stackelberg solution of the quality stage, see Lambertini (1996).
} 
absolute cost advantage over the rival, adding up this element to the fact that it is supplying the high-quality good entails that firm $H$ is ultimately outperforming firm $L$ in all respects. Furthermore, it is the only active firm when $\Delta \bar{c} \leq-\left[27 \gamma-32 s(1-\beta)^{2}\right] /(48 \gamma s)$. In this latter case it can be easily verified that:

$$
q_{H}=\frac{(2 \bar{\theta}-1)}{4 s}, q_{L}=\frac{(\bar{\theta}-2)}{2 s}
$$

i.e. firm $H$ that supplies the quality it would produce were it appointed the first mover advantage at the second stage of the game, while firm $L$ 's quality lies below the lower bound of the interval of preferred qualities.

Lastly, we sketch the case where $\Delta \bar{c}=0$, i.e. the firm-specific component of the marginal cost before process innovation is equal across firms. While it remains true that at equilibrium firm $H$ produces a good of higher quality than firm $L$, and it charges a higher price, demand is equally split between the firms and each one serves half of the market. Moreover, the investment effort in R\&D is the same for both firms and amounts to:

$$
\left.k_{H}^{*}\right|_{\Delta \bar{c}=0}=\left.k_{L}^{*}\right|_{\Delta \bar{c}=0}=\frac{(1-\beta)}{3 \gamma} .
$$

Similarly, equilibrium profits are symmetric and equal to:

$$
\left.\pi_{H}^{*}\right|_{\Delta \bar{c}=0}=\left.\pi_{L}^{*}\right|_{\Delta \bar{c}=0}=\frac{\left[27 \gamma-16 s(1-\beta)^{2}\right]}{144 \gamma s} .
$$

This last result directly derives from the isomorphic structure of our game with respect to the Hotelling model with quadratic transportation cost, as demonstrated by Cremer and Thisse (1991). Once firms are symmetric since the very beginning, it follows that, notwithstanding the equilibrium's quality difference, profits and demands are exactly the same.

To complete the equilibrium analysis, there remains to check the incentives for a firm to leapfrog the rival at the quality stage. In fact, Proposition 
3 may legitimately raise the issue of whether there exists such an incentive for the high-quality firm to leapfrog the rival downwards, given that $\Delta \bar{c}$ is positive and lies in the range where firm $H$ 's market share and profits are nil. I.e., is there a profitable deviation from $q_{H}^{*}$, whereby firm $H$ could indeed gain by relocating in the range $\left(0, q_{L}^{*}\right)$ ?

In order to investigate this perspective, we shall assume that prices are flexible, as well as the quality level chosen by the high-quality firm. On the contrary, we keep fixed the quality level of firm $L, q_{L}^{*}$ in (17) as well as R\&D efforts, $k_{H}^{*}=0$ and $\left.k_{L}^{*}\right|_{k_{H}^{*}=0}$ as in (21). That is, we examine the profitability of a unilateral deviation by firm $H$ at the quality stage, given (i) the quality supplied by the rival and (ii) the sunk decisions of both at the first stage. ${ }^{4}$ In the Appendix we prove the following:

Proposition 4 For all $|\Delta \bar{c}|>\left[27 \gamma-32 s(1-\beta)^{2}\right] /(48 \gamma s)$, the duopoly equilibrium does not exist.

Note that, by symmetry, we cover also the case where $\Delta \bar{c}<0$ and the low-quality firm examines the profitability of leapfrogging the rival upwards, starting from a situation where $k_{L}^{*}=x_{L}^{*}=\pi_{L}^{*}=0$ in that $|\Delta \bar{c}|>$ $\left[27 \gamma-32 s(1-\beta)^{2}\right] /(48 \gamma s)$.

Another related question is the following: is there any incentive to leafrog in either direction when $|\Delta \bar{c}|<\left[27 \gamma-32 s(1-\beta)^{2}\right] /(48 \gamma s)$ ? A simple intuitive argument shows that this is not the case. As already remarked, Cremer and Thisse (1991) proved that with $\Delta \bar{c}=0$ the present model is isomorphic to a spatial differentiation model with quadratic transportation costs (as in d'Aspremont et al., 1979). In the latter, if firms are located respectively to the left and right of the average (and median) consumer, then leapfrogging is not profitable. Likewise, in the present model of vertical differentiation,

\footnotetext{
${ }^{4}$ This is the standard approach to leapfrogging in vertical differentiation models. See Motta, Thisse and Cabrales (1997) and Rosenkranz (1997).
} 
leapfrogging incentives are absent if both profits are positive and firms are located respectively above and below the quality which is preferred by the median (and average) consumer, $q_{M}=(2 \bar{\theta}-1) /(4 s)$, for the following reason. Suppose first that $\Delta \bar{c}=0$. In such a case, leapfrogging by either firm is not profitable if $q_{L}<q_{M}<q_{H}$ as it is not in the corresponding horizontal model. Alternatively suppose $|\Delta \bar{c}| \in\left(0,\left[27 \gamma-32 s(1-\beta)^{2}\right] /(48 \gamma s)\right)$. If so, a fortiori, the firm bearing the highest $\bar{c}_{i}$ has no incentive to leapfrog precisely because it is less efficient than the rival.

\section{$4 \quad \mathrm{R} \& \mathrm{D}$ cooperation}

If firms cooperate at the $R \& D$ stage, they can activate either a joint venture or a cartel. The first case would consist in funding research activities carried out in a single lab, with firms sharing its cost. The outcome would be a single technology whereby firms would share the same marginal cost. This entails that the joint venture would lead us back to the standard Hotellinglike symmetric model we know from Cremer and Thisse (1991; 1994), inter alia. If instead firms create an R\&D cartel, they coordinate the activities carried out in their respective labs so as to maximise joint profits. Given that firms play noncooperatively in the quality as well as in the price space, the solution of the second and the third stage is the same as in the previous section. In the first stage, the objective of the R\&D cartel is to maximise the sum of firms' profits appearing in (8) w.r.t. $k_{H}$ and $k_{L}$ :

$$
\Pi^{C}=\frac{[16 s \Delta \bar{c}-9]^{2}+[16 s \Delta \bar{c}+9]^{2}}{432 s}-\gamma\left(k_{H}^{2}+k_{L}^{2}\right)
$$

where superscript $C$ stands for cartel and $c_{i}=\bar{c}_{i}-k_{i}-\beta k_{j}$.

The first order conditions (FOCs) approach yields to the following pair 
of R\&D efforts as candidate maximizers of the cartel's profit:

$$
k_{H}=-\frac{32 \Delta \bar{c}(1-\beta) s}{27 \gamma-64(1-\beta)^{2} s} ; k_{L}=\frac{32 \Delta \bar{c}(1-\beta) s}{27 \gamma-64(1-\beta)^{2} s}
$$

whereby it is evident that $k_{H}$ and $k_{L}$ have opposite sign, and therefore they cannot be simultaneously positive. This entails that, in order for the solution to be economically meaningful, we must impose that, whenever either of the above expressions is negative, the actual $R \& D$ effort of the firm is in fact nil.

A quick exam of second order conditions:

$$
\begin{gathered}
\frac{\partial^{2} \Pi^{C}}{\partial k_{i}}=\frac{64}{27}(1-\beta)^{2} s-2 \gamma \leq 0 \\
\mathcal{H}=\left[\begin{array}{cc}
\frac{64}{27}(1-\beta)^{2} s-2 \gamma & -\frac{64}{27}(1-\beta)^{2} s \\
-\frac{64}{27}(1-\beta)^{2} s & \frac{64}{27}(1-\beta)^{2} s-2 \gamma
\end{array}\right]
\end{gathered}
$$

reveals that the necessary and sufficient condition for local concavity and asymptotic stability is $\gamma>64 s(1-\beta)^{2} / 27$. Provided this condition is satisfied, we have two opposite cases.

- $\Delta \bar{c}>0$, and consequently $k_{H}=0$. It follows that the optimal R\&D effort of firm $L$ is:

$$
k_{L}^{C}=\frac{32 \Delta \bar{c}(1-\beta) s}{27 \gamma-32(1-\beta)^{2} s} .
$$

- $\Delta \bar{c}<0$, and consequently $k_{L}=0$. The optimal R\&D effort of firm $H$ is therefore given by:

$$
k_{H}^{C}=-\frac{32 \Delta \bar{c}(1-\beta) s}{27 \gamma-32(1-\beta)^{2} s} .
$$

This has the immediate implication stated in the following Proposition: 
Proposition 5 Provided that the condition ensuring local concavity and asymptitic stability is met, then (i) if $\Delta \bar{c}>0, k_{L}^{C}>0$ and $k_{H}^{C}=0$; (ii) if $\Delta \bar{c}<0$, $k_{L}^{C}=0$ and $k_{H}^{C}>0$; (iii) if $\Delta \bar{c}=0, k_{L}^{C}=k_{H}^{C}=0$.

Summing up, we have seen that R\&D cartelisation induces to shut down the R\&D lab of the firm initially characterised by the lowest efficiency level. The entire brunt of R\&D activity is borne by the firm whose initial marginal cost was $\min \left\{\bar{c}_{H}, \bar{c}_{L}\right\}$. Moreover, in the special case in which the initial efficiency level of the two firms were the same, then the cartel would be altogether inactive with respect to process innovation, leading to a joint profit equal to

$$
\left.\Pi^{C}\right|_{\Delta \bar{c}=0}=\frac{3}{8 s} .
$$

The last point calls for a more detailed explanation, referring in particular to what we have seen in the non cooperative scenario when $\Delta \bar{c}=0$. When firms compete at the process innovation stage, they invest the same positive amount in R\&D to cut the firm-specific cost. However, this does not provide a significant advantage for either firm, and indeed equilibrium profits and demands are the same. This amounts to saying that process innovation results in a waste of resources, as the symmetric structure of the model prevents to gain a competitive edge over the rival. When firms form a cartel and cooperate at the process $R \& D$ stage they internalize the inutility of carrying out such activity and therefore they do not invest at all. It can be easily checked that $\left.\Pi^{C}\right|_{\Delta \bar{c}=0}>\left(\left.\pi_{H}^{*}\right|_{\Delta \bar{c}=0}+\left.\pi_{L}^{*}\right|_{\Delta \bar{c}=0}\right)$, so that firms would always prefer to coordinate their R\&D efforts.

\section{Concluding remarks}

We have investigated a vertically differentiated duopoly where firms may activate $\mathrm{R} \& \mathrm{D}$ projects for process and product innovation before competing à 
la Bertrand on the market. Product innovation is conceived as quality improvement. The foregoing analysis has yielded four main results: (i) process and product innovation are complements for the low-quality firm while they are substitutes for the high-quality firm; (ii) the firm which is initially more efficient than the rival does invest more than the rival in process innovation; (iii) if the initial differential between marginal costs is large enough, then result (ii) ultimately entails that the less efficient firm has no demand and the duopoly equilibrium does not exist; (iv) when firms cooperate at the process $R \& D$ stage, we find out that only the most efficient invests when they are asymmetric, while no investment is carried out when they start from a symmetric position.

\section{Appendix}

\section{Proof of Proposition 4}

The new demand system is defined as

$$
\begin{aligned}
x_{L} & =\bar{\theta}-\tilde{\theta} ; x_{\ell}=\widetilde{\theta}-\underline{\theta} \\
\widetilde{\theta} & =\frac{p_{L}-p_{\ell}}{q_{L}^{*}-q_{\ell}}
\end{aligned}
$$

where subscript $\ell$ stands for leapfrogging. The relevant objective functions at the third stage are:

$$
\begin{aligned}
\pi_{L} & =\left(p_{L}-c_{L}^{*}-s q_{L}^{*}\right) x_{L} \\
\pi_{\ell} & =\left(p_{\ell}-\bar{c}_{H}-s q_{\ell}\right) x_{\ell}
\end{aligned}
$$

where the marginal costs of firms are determined by their R\&D efforts $k_{H}^{*}=0$ and $\left.k_{L}^{*}\right|_{k_{H}^{*}=0}$, so that the leapfrogger bears $\bar{c}_{H}$. Candidate optimal prices are:

$$
\begin{aligned}
p_{L}^{*} & =\frac{2 c_{L}^{*}+\bar{c}_{H}+(\bar{\theta}-1)\left(q_{L}^{*}-q_{\ell}\right)+s\left(2\left(q_{L}^{*}\right)^{2}+q_{\ell}^{2}\right)}{3} \\
p_{\ell}^{*} & =\frac{c_{L}^{*}+2 \bar{c}_{H}+(2-\bar{\theta})\left(q_{L}^{*}-q_{\ell}\right)+s\left(\left(q_{L}^{*}\right)^{2}+2 q_{\ell}^{2}\right)}{3}
\end{aligned}
$$


As a result, the profits of the leapfrogging firm are

$$
\pi_{\ell}=\frac{\left[c_{L}^{*}-\bar{c}_{H}+\left(q_{L}^{*}-q_{\ell}\right)\left(2-\bar{\theta}+s\left(q_{L}^{*}+q_{\ell}\right)\right)\right]^{2}}{9\left(q_{L}^{*}-q_{\ell}\right)}
$$

which seems to be positive. However, in order to verify whether the r.h.s. of (37) is indeed positive, we have to check whether $x_{\ell}>0$. Using (17), we have:

$x_{\ell}=\frac{\left[3(4 \bar{\theta}-11)+8 s\left(2\left(\bar{c}_{H}-c_{L}^{*}\right)-3 q_{\ell}\right)\right]\left[3(5-4 \bar{\theta})+8 s\left(2\left(\bar{c}_{H}-c_{L}^{*}\right)+3 q_{\ell}\right)\right]}{72\left[3(4 \bar{\theta}-5)+8 s\left(2\left(\bar{c}_{H}-c_{L}^{*}\right)-3 q_{\ell}\right)\right]}$

where the denominator is positive for all

$$
q_{\ell}<\frac{16 s\left(\bar{c}_{H}-c_{L}^{*}\right)+3(4 \bar{\theta}-5)}{24 s} .
$$

Now note that the above condition is surely satisfied as the r.h.s. expression is equivalent to $q_{L}^{*}$ in (5). Consequently, $x_{\ell}$ and $\pi_{\ell}$ are positive iff the numerator of $x_{\ell}$ is positive. In order to verify this, observe that

$$
\begin{gathered}
3(4 \bar{\theta}-11)+8 s\left(2\left(\bar{c}_{H}-c_{L}^{*}\right)-3 q_{\ell}\right) \gtrless 0 \Leftrightarrow \\
q_{\ell} \lessgtr \frac{16 s\left(\bar{c}_{H}-c_{L}^{*}\right)+3(4 \bar{\theta}-11)}{24 s} \equiv q_{\ell 1}
\end{gathered}
$$

and

$$
\begin{gathered}
3(5-4 \bar{\theta})+8 s\left(2\left(\bar{c}_{H}-c_{L}^{*}\right)+3 q_{\ell}\right) \gtrless 0 \Leftrightarrow \\
q_{\ell} \gtrless \frac{3(4 \bar{\theta}-5)-16 s\left(\bar{c}_{H}-c_{L}^{*}\right)}{24 s} \equiv q_{\ell 2}
\end{gathered}
$$

with both $q_{\ell 1}$ and $q_{\ell 2}$ smaller than $q_{L}^{*}$ in (5) or, equivalently, the r.h.s. of (39). Therefore, irrespective of whether $q_{\ell 1}>q_{\ell 2}$ or the opposite,

$$
x_{\ell}, \pi_{\ell}>0 \forall q_{\ell} \in\left(\min \left(q_{\ell 1}, q_{\ell 2}\right), \max \left(q_{\ell 1}, q_{\ell 2}\right)\right) .
$$

Obviously, once the deviating firm, that was previously the high-quality supplier, has leapfrogged the rival downwards, the latter has a strict incentive to 
reoptimise. In so doing, the former low-quality firm can indeed exploit the fact that now it has become the new high-quality supplier and enjoys an advantage w.r.t. the relative size of marginal costs, as now we have that $\Delta \bar{c}_{\ell}<0$ and yet $\left|\Delta \bar{c}_{\ell}\right|>\left[27 \gamma-32 s(1-\beta)^{2}\right] /(48 \gamma s)$. On the basis of Proposition 3, once firm $L$ has reoptimised its own quality, the leapfrogger is left with zero demand. 


\section{References}

[1] Athey, S. and A. Schmutzler (1995), Product and Process Flexibility in an Innovative Environment, RAND Journal of Economics, 26, 557-574.

[2] Beath, J., Y. Katsoulacos and D. Ulph (1987), Sequential Product Innovation and Industry Evolution, Economic Journal, 97 (Supplement), $32-43$.

[3] Bonanno, G. and B. Haworth (1998), Intensity of Competition and the Choice between Product and Process Innovation, International Journal of Industrial Organization, 16, 495-510.

[4] Cohen, W.M. and S. Klepper (1996), Firm Size and the Nature of Innovation within Industries: The Case of Process and Product R\&D, Review of Economics and Statistics, 78, 232-243.

[5] Cremer, H. and J.-F. Thisse (1991), Location Models of Horizontal Differentiation: A Special Case of Vertical Differentiation Models, Journal of Industrial Economics, 39, 383-390.

[6] Cremer, H. and J.-F. Thisse (1994), Commodity Taxation in a Differentiated Oligopoly, International Economic Review, 35, 613-33.

[7] d'Aspremont, C., Gabszewicz, J.J., and Thisse, J.-F. (1979), On Hotelling's 'Stability in Competition', Econometrica, 47, 1045-50.

[8] d'Aspremont, C. and A. Jacquemin (1988), Cooperative and Noncooperative R\&D in Duopoly with Spillovers, American Economic Review, 78, 1133-37.

[9] d'Aspremont, C. and A. Jacquemin (1990), Erratum, American Economic Review, 80, 641-2. 
[10] Dutta, P.K., S. Lach and A. Rustichini (1995), Better Late than Early: Vertical Differentiation in the Adoption of a New Technology, Journal of Economics and Management Strategy, 4, 563-89.

[11] Gabszewicz, J.J. and J.-F. Thisse (1979), Price Competition, Quality and Income Disparities, Journal of Economic Theory, 20, 340-59.

[12] Gabszewicz, J.J. and J.-F. Thisse (1980), Entry (and Exit) in a Differentiated Industry, Journal of Economic Theory, 22, 327-38.

[13] Henriques, I. (1990), Cooperative and Noncooperative R\&D with Spillovers: Comment, American Economic Review, 80, 638-40.

[14] Lambertini, L. (1996), Choosing Roles in a Duopoly for Endogenously Differentiated Products, Australian Economic Papers, 35, 205-24.

[15] Lambertini, L. (2003), The Monopolist's Optimal R\&D Portfolio, Oxford Economic Papers, 55, 561-78.

[16] Lambertini, L. (2004), Process and Product R\&D by a Multiproduct Monopolist: A Reply to Lin, Oxford Economic Papers, 56, 745-49.

[17] Lambertini, L. and R. Orsini (2000), Process and Product Innovation in a Vertically Differentiated Monopoly, Economics Letters, 68, 333-37.

[18] Lambertini, L. and P. Tedeschi (2006), On the Social Desirability of Patents for Sequential Innovations in a Vertically Differentiated Market, Journal of Economics, forthcoming.

[19] Lehmann-Grube, U. (1997), Strategic Choice of Quality when Quality is Costly: The Persistence of the High-Quality Advantage, RAND Journal of Economics, 28, 372-84. 
[20] Lin, P. (2004), Process and Product R\&D by a Multiproduct Monopolist, Oxford Economic Papers, 56, 735-43.

[21] Lin, P. and K. Saggi (2002), Product Differentiation, Process R\&D, and the Nature of Market Competition, European Economic Review, 46, 201-11.

[22] Motta, M. (1992), Cooperative R\&D and Vertical Product Differentiation, International Journal of Industrial Organization, 10, 643-61.

[23] Motta, M., J.-F. Thisse and A. Cabrales (1997), On the Persistence of Leadership or Leapfrogging in International Trade, International Economic Review, 38, 809-24

[24] Rosenkranz, S. (1995), Innovation and Cooperation under Vertical Product Differentiation, International Journal of Industrial Organization, 13, $1-22$.

[25] Rosenkranz, S. (1997), Quality Improvements and the Incentive to Leapfrog, International Journal of Industrial Organization, 15, 243-61.

[26] Schmitt, P.M. (2003), A Vertically Differentiated Duopoly with Marginal Cost Differentials, International Game Theory Review, 5, 7381.

[27] Shaked, A. and J. Sutton (1982), Relaxing Price Competition through Product Differentiation, Review of Economic Studies, 49, 3-13.

[28] Shaked, A. and J. Sutton (1983), Natural Oligopolies, Econometrica, 51, 1469-83.

[29] van Dijk, T. (1996), Patent Height and Competition in Product Improvements, Journal of Industrial Economics, 44, 151-67. 